\title{
Л.Ю. Фуксон
}

\section{Еще раз о смысле названия «Горя от ума»}

Осмысление названия произведения невозможно рассматривать иначе как осмысление самого произведения ${ }^{1}$. Название текста скорее обещает, предсказывает сбывающийся лишь в дальнейшем чтении смысл. Дело здесь даже не в том, что в названии пьесы фигурируют абстрактные понятия, нуждающиеся в эстетической инкарнации, олицетворении. Приходится исходить из того, что художественный смысл название содержит лишь в связи с последующим, в контексте некой образной логики. Предлагаемая статья - попытка выяснения этой художественной логики как предварительная работа для возможного прочтения названия пьесы «Горе от ума».

Когда мы, думая над названием пьесы, интерпретируем слово «от» как указание на причинность (ум - причина горя), то название произведения Грибоедова может восприниматься как некий неразрешимый конфликт ума и жизни, перекликаясь с пословицей, называющей комедию Островского, - «Правда - хорошо, а счастье лучше». Само понятие «ум» в драме выявляет свою сложность. Это выражается, например, в противоположности установок Фамусова и Чацкого. Фамусов заканчивает свой рассказ о Максиме Петровиче следующим комментарием:

А? Как по-вашему? По-нашему - смышлен.

Упал он больно, встал здорово. $(2,2)^{2}$

Здесь ум («смышленость») заключается в признании приоритета жизни и ее практического интереса над умом. Это как раз «здоровое» их соотношение, с точки зрения Фамусова, которого падение Максима Петровича, его шутовство и самоуничижение восхищают. Но у Чацкого все это вызывает презрение, так как для него не ум должен исходить из требований жизни, а наоборот. Поэтому случайность возникновения слуха о сумасшествии Чацкого мнимая. Гордец Чацкий полная противоположность Максима Петровича - ненормален для Фамусова, так что тот имеет полное право сказать сомневающимся в сумасшествии героя:

Чего сомнительно? Я первый, я открыл!

Давно дивлюсь я, как никто его не свяжет! $(3,21)$

Этому фамусовскому «уму», подстраивающемуся под житейский интерес, противостоит «ум» Чацкого, игнорирующий внерассудочную основу жизни, ее «умонепостижимость».

Недоверчивость Чацкого к тому, что София любит Молчалина, которой как художественной находкой восхищался Пушкин, как раз демонстрирует эту грани-

\footnotetext{
${ }^{1}$ См., например: [Тюпа, 2000, с. 9-10].

2 Здесь и ниже произведения А.С. Грибоедова цитируются по изданию [Грибоедов, 1987] с указанием страниц в круглых скобках.
} 
цу «ума» героя с репутацией умника. В мире пьесы образуется особая, необъяснимая «цепочка любви», о чем говорит Лиза:

Она к нему, а он ко мне,

А я...одна лишь я любви до смерти трушу. -

А как не полюбить буфетчика Петрушу! $(2,14)$

Итак: Чацкий $\wedge$ София $\wedge$ Молчалин $\wedge$ Лиза $\wedge$ буфетчик Петруша. В признании Лизы мы видим единственного в комедии «счастливца», который встречается еще в начале второго действия, когда к нему обращается Фамусов:

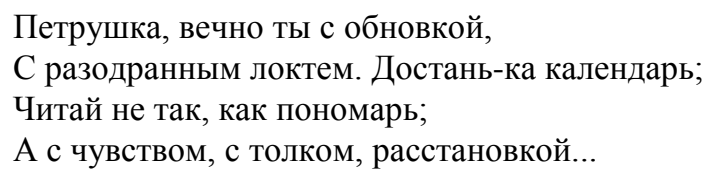

Здесь персонаж дан как в потоке времени («обновка», «календарь»), так и в модусе своего безразличия к нему. Такая беззаботность связана в пьесе с темой счастья: «Счастливые часов не наблюдают».Если мы поставим рядом два известных выражения - «горе от ума» и «счастливые часов не наблюдают», - то обнаружится нерасторжимая связь понятий «счастье» («горе») и «время», «ум» и «время». «Наблюдение» течения времени («часов») есть не-счастье. Преходящий характер жизни печален, а счастье, наоборот, связано с отключением от этой временности жизни. Причем такое счастливое отключение есть само-забвение, без-умие («ненаблюдение»).

Если истина печальна, то ум, стремясь к истине, приносит горе. Ситуации и образы комедии Грибоедова преломляют эту древнюю мысль о горестном характере ума и познания (книга Экклезиаста, 1-2). Смысл названия, лежащий на поверхности, говорит о противоречии знания и жизни, как запрет в Эдеме (Бытие, 23). У горя от ума есть смысл, который не разделяет, а, наоборот, объединяет различных персонажей произведения Грибоедова и обстоятельства, в которых они оказываются.

Так предварительно могут быть намечены контуры осмысления названия пьесы: ум и безумие, счастье и горе - все это связано с темой времени.

Сравним несколько ситуаций, в которых фигурирует время. Первая фраза, звучащая в пьесе, принадлежит Лизе: «Светает!... Ах! Как скоро ночь минула!» (1, 1). Служанка сетует на быстрый ход времени, как и, чуть позже, госпожа: «И свет и грусть. Как быстры ночи!» $(1,3)$. Правда, у этих сетований различные мотивы. Одна героиня (Лиза) - невыспавшаяся, а вторая (София) - влюбленная. Но в обоих случаях течение времени воспринимается отрицательно.

Таков же образ времени во встрече Чацкого со старым другом Горичем, который признается: «Да, брат, теперь не так... Теперь, брат, я не тот... Эх, братец! Славное тогда житье-то было» $(3,6)$. То есть «тогда» лучше, чем «теперь».

В пьесе постоянно демонстрируется переход от славного к скучному, от счастья к несчастью, от любви - к разочарованию. София рассказывает свой сон, в котором именно такая перипетия: «сначала» - идиллическая картина «цветистого луга» и явления «милого человека», «потом пропало все...» $(1,4)$. Немного позже София в ответ на опасения Лизы перед молвой, то есть перед раскрытием тайны, говорит:

Подумаешь, как счастье своенравно!

Бывает хуже, с рук сойдет; 
Когда ж печальное ничто на ум нейдет,

Забылись музыкой, и время шло так плавно;

Судьба как будто берегла;

Ни беспокойства, ни сомненья...

А горе ждет из-за угла. $(1,5)$

Здесь это «забылись музыкой» означает ту ситуацию счастливого неведения, без-умия, не подверженного сомнению (ср. далее: «Блажен, кто верует...»(1,7)), которая связана с «плавным» ходом времени (то есть незаметным для «счастливых»).

Эта сентенция о своенравности счастья затем реализуется в ситуации горестного откровения истины о Молчалине. Именно потому, что счастье - неведение, «ум» в пьесе - это не некое постоянное («субстанциальное») качество, а событие откровения горькой правды. Именно этой логикой объясняется последнее пожелание Чацкого Фамусову: «Желаю вам дремать в неведеньи счастливом...» $(4,14)$.

Комический вариант того же самого читатель пьесы находит в Лизином рассказе о тетушке Софии, от которой сбежал молодой француз и которая «хотела схоронить свою досаду», но «не сумела»: «Забыла волосы чернить / И через три дни поседела» $(1,5)$. Здесь горе откровения соединяется с темой старости (седина - знак преходящести, временности жизни, а попытка ее скрыть - обреченная на неуспех без-умная борьба со временем).

Можно сравнить два параллельных отзыва персонажей о своем возрасте:

Фамусов:

Ах! батюшка, нашел загадку,

Не весел я!.. В мои лета

Не можно же пускаться мне вприсядку! $(2,2)$

Молчалин:

В мои лета не должно сметь

Свое суждение иметь $(3,3)$

В первом высказывании имеется в виду возраст ума, легко справляющегося с загадками. Но разгадка грустная: это старость, которой не до веселья. Во второй сентенции речь идет о том, что на ум, связанный с самостоятельным суждением, нужно право возраста. Молодому человеку ум как бы неприличен. Эта параллель, как и другие наблюдения, выявляет направление хода времени человеческой жизни: от возраста без-умной (не смеющей «свое суждение иметь») веселости - к возрасту печальной истины.

Лиза в конце первого явления переводит часы, чтобы они своим боем вернули хозяйку к реальности. Это жест здравого смысла («ума»), разрушающий любовную идиллию, о которой сама Лиза говорит: «Ах! амур проклятый!»

Софья замечает о прошедшем свидании с Молчалиным:

Ночь целую с кем можно так провесть!

Сидим, а на дворе давно уж побелело... $(1,5)$

Это своего рода парафраз сентенции из третьего явления («Счастливые часов не наблюдают»), так как внутри, где «сидим», - в зоне счастья - время как бы остановилось или идет «плавно» (незаметно).

Репетилов сетует в разговоре с Чацким:

Ругай меня, я сам кляну свое рожденье, Когда подумаю, как время убивал!.. $(4,4)$ 
Дальнейшее описание «тайных собраний» с «соком умной молодежи» носит, конечно, пародийный характер, однако в этом комическом варианте горя от ума та же, уже выявленная, закономерность: как только герой начинает «часы наблюдать» - он теряет счастливую беззаботность и клянет «свое рожденье».

Тема времени, конечно, тесно связана с образом Чацкого, плач которого при отъезде три года назад оказался пророческим: «Недаром, Лиза, плачу, / Кому известно, что найду я воротясь? И сколько, может быть, утрачу!» $(1,5)$ Уже в первом появлении Чацкого звучит элегическая интонация воспоминания: «Где время то? где возраст тот невинный...» $(1,7)$, на что София отвечает: «Ребячество!». Здесь действует та же самая логика: возраст блаженного неведения - детство, на другом же полюсе - время горькой истины, обнаружения седины старости. Чацкий говорит позже о детстве: «...Когда все мягко так? и нежно, и незрело?» $(1,7)$. Время нежности (и, соответственно, счастья) не совпадает с временем зрелости. Созревает именно горе. Поэтому «горе» и «ум» (= зрелость) так связаны, а с сердцем (= нежностью) ум «не в ладу» $(1,7)$.

Чацкий просит разрешения побыть несколько минут в комнате Софии:

Там стены, воздух - все приятно!

Согреют, оживят, мне отдохнуть дадут

Воспоминания об том, что невозвратно! $(3,2)$

Безрассудное желание согревает, но своего рода «ложкой дегтя» является отрезвляющее сознание невозвратности времени.

По тому же принципу, согласно которому понятие «ум» в произведении Грибоедова проясняется не только в связи с «горем», но и, наоборот, в связи со «счастьем», обратимся ко второму действию, где речь идет о двоюродном брате Скалозуба:

Фамусов.

Любезный человек, и посмотреть - так хват, Прекрасный человек двоюродный ваш брат. Скалозуб.

Но крепко набрался каких-то новых правил.

Чин следовал ему: он службу вдруг оставил, В деревне книги стал читать.

Фамусов.

Вот молодость!.. - читать!.. а после хвать!..

Вы повели себя исправно,

Давно полковники, а служите недавно. $(2,5)$

Слова Фамусова («...читать!.. а после хвать!..») перефразируют название «Горя от ума». Счастливая дорога - карьера Скалозуба - в стороне от умственных занятий, которые выбрал его брат. Еще в первом действии соединяются эти две характеристики Скалозуба: 1) «И золотой мешок, и метит в генералы» (Лиза); 2) «Он слова умного не выговорил сроду...» (София). А сам он отвечает на предложение Репетилова: «Ученостью меня не обморочишь...» $(4,5)$. В отзыве Скалозуба о своем брате обращают на себя внимание слова: «...крепко набрался каких-то новых правил...». Здесь отчетливо звучит тот же мотив времени, «наблюдение» которого («крепко набрался») ведет к некой «учености», но уводит от «счастья».

Отзыв Чацкого о Молчалине подразумевает некую общественную тенденцию: 
А впрочем он дойдет до степеней известных,

Ведь нынче любят бессловесных. $(1,7)$

Это «нынче» открывает горестный смысл течения времени, героем которого становится бессловесный (то есть безличный, угождающий «всем людям без изъятья»; здесь, конечно, подразумевается еще оскорбительное «скот»). Но нечаянно высказывается здесь истина отношений Софии и Молчалина, еще неведомая Чацкому. Смысл понятия «ум» (событие обнаружения горькой истины, утрачивания иллюзий) относится поэтому и к Чацкому:

Ну вот и день прошел, и с ним

Все призраки, весь чад и дым

Надежд, которые мне душу наполняли. $(4,3)$

Решение Чацкого спрятаться и все выяснить - это шаг навстречу истине («ум»), но и шаг навстречу горю: «Уж коли горе пить, / Так лучше сразу...» $(4,10)$. В этой сцене истина обнаруживается сразу как бы на двух уровнях: для Софии о Молчалине и для Чацкого о Софии. И на обоих уровнях она печальна. Так что к Софии название пьесы тоже в полной мере относится.

Итак, если «ум» в пьесе не что иное, как состояние перехода от лжи к истине, от видимости (маски) к реальности (лицу), событие разоблачения, то можно сказать, что это разоблачение носит горестный характер и лицо оказывается как бы всегда хуже маски. Например, Горич говорит Загорецкому:

Я правду об тебе порасскажу такую,

Что хуже всякой лжи ... $(3,9)$

«Правда» в произведении Грибоедова всегда «хуже» лжи. Так, по-видимому, следует понимать смысл его названия. Чацкий занимает в изображенном мире в основном как раз позицию разоблачения, сохраняя «сатирическую», насмешливую позу от самого своего появления в первом действии (когда София говорит о нем «в сторону»: «Не человек, змея!» $[1,7])$ вплоть до последнего монолога перед отъездом $(4,14)$. Однако эта позиция и делает героя-разоблачителя страдающей стороной по художественной логике, обозначенной названием. Все остальные персонажи как бы инстинктивно чувствуют, догадываются о горестном характере откровения истины и поэтому больше всего боятся разоблачения. Пьеса начинается с забот Лизы о сокрытии тайны отношений ее госпожи и Молчалина: «Грех не беда, молва не хороша» $(1,5)$. Молчалин говорит по поводу обморока Софии: «Ах! злые языки страшнее пистолета» $(2,11)$. А последние слова произведения это сетования Фамусова:

А ты меня решилась уморить?

Моя судьба еще ли не плачевна?

$\mathrm{Ax}$ ! боже мой! Что станет говорить

Княгиня Марья Алексевна! $(4,15)$

Вот почему насмешник Чацкий всеми так легко принимается за сумасшедшего: он стремится открыть то, чего все остальные, наоборот, избегают, - само реальное положение дел, горестную истину.

Как показывают предыдущие наблюдения, название пьесы «Горе от ума» вовсе не проводит границу между умниками и глупцами. «Ум» в произведении Грибоедова - это не статичная характеристика какого-либо одного персонажа, а событие выяснения горестной истины, охватывающее весь художественный мир. 
Вот почему так важен для понимания названия пьесы динамичный аспект художественного времени.

Мы выяснили один смысловой аспект названия пьесы, сопоставив его с высказыванием «Счастливые часов не наблюдают». Другой важный - топологический - оттенок смысла понятия «ум» в пьесе выявляется в связи с тем, что София говорит Лизе о Чацком:

Ах! если любит кто кого,

Зачем ума искать и ездить так далеко? $(1,5)$

«Ум» в комедии оказывается антонимом «любви», причем ум вообще удаляет от жизни, где главное - счастье близости, как это описывает София:

Возьмет он руку, к сердцу жмет,

Из глубины души вздохнет,

Ни слова вольного, и так вся ночь проходит,

Рука с рукой, и глаз с меня не сводит... $(1,5)$

Если отъезд (удаление) Чацкого - это поиски ума, сопряженные с утратой счастья, то зона близости - Москва - в понимании Молчалина связана с весельем:

Ну, право, что бы вам в Москве у нас служить?

И награжденья брать и весело пожить? $(3,3)$

Те же категории близости и далекости обнаруживаются в словах Фамусова и Чацкого. Фамусов в беседе со Скалозубом замечает: «...Ну как не порадеть родному человечку!» $(2,5)$. Чацкий же, наоборот, хочет служить «делу, а не лицам» $(2,2)$, то есть «служить», а не «прислуживаться». Абстрактное «дело» здесь удаляет от «лиц» близких («родных человечков»). Поэтому для Фамусова, как и для его дочери, очень важно понятие «семья»: Фамусов рассуждает о женихе:

Другой хоть прытче будь, надутый всяким чванством, Пускай себе разумником слыви,

А в семью не включат... $(2,5)$

Это относится и к «гордецу» Чацкому: гордость удаляет от «семьи». Об этом же говорит София в диалоге с Чацким о Молчалине:

Конечно, нет в нем этого ума,

Что гений для иных, а для иных чума,

Который скор, блестящ и скоро опротивит (...)

Да этакий ли ум семейство осчастливит? $(3,1)$

«Ум» здесь удаляет, а не приближает, и поэтому является антонимом «счастья». (Кстати, вообще в русском языке недалекость синоним глупости). По сути то же самое мы видим в презрительном отзыве Чацкого о Молчалине:

А чем не муж? Ума в нем только мало;

Но чтоб иметь детей,

Кому ума не доставало? $(3,3)$

В высказываниях различных персонажей повторяется одна логика, по которой на одном полюсе находится образ семьи и тесных отношений «родных чело- 
вечков»; причем обманчивость этих отношений как раз и делает их «счастливыми», благополучными. На другом полюсе - «ум», то есть горестная истина, удаляющая от людей. Это отталкивающее разоблачение обмана. Узрение сущности отвращает от существования. По-видимому, можно считать в определенном смысле персонификацией этих полюсов Фамусова и Чацкого, о противоположности установок которых уже говорилось ранее. Во-первых, это два поколения, отстаивающие либо старину, либо новизну, соответственно противоположным образом относящиеся к времени. Совет Фамусова «Учились бы, на старших глядя» $(2,2)$ как бы останавливает время: младшее поколение должно повторить жизнь старшего. Чацкий же, наоборот, воплощает движение времени: «Нет, нынче свет уж не таков... Вольнее всякий дышит» $(2,2)$. Фамусова можно назвать человеком дома. Для него, как уже было отмечено, важное значение имеют семья и Москва (эти понятия отчасти сливаются - 2, 5). Чацкий - человек дороги. Он появляется в Москве после того, как «хотел объехать целый свет, и не объехал сотой доли» $(1,9)$, и уезжает со словами: «Вон из Москвы... Карету мне, карету» $(4,14)$. Очевидно, понятие дороги (и дали, с ней связанной) примыкает к образам горестного движения времени и ума, которого ездил «искать» герой.

К понятию «ум» в пьесе подводит также связанный с ним образный ряд смеха. Здесь не имеется в виду комедийная трактовка каких-то событий, когда смех автора (и читателя) «не долетает до ушей» смешного героя. В этом смысле иногда встречающееся определение «Горя от ума» как комедии сомнительно. Как показали предыдущие наблюдения, художественное время пьесы обнаруживает переход от счастья к горю, что, по-видимому, противоречит старой аристотелевской характеристике комедии. Поэтому, несмотря на наличие отдельных комических эпизодов в «Горе от ума», едва ли стоит здесь говорить о смехе как способе художественного изображения. Однако необходим учет смеха как предмета изображения. Итак, понятия «ум» и «смех» в пьесе связаны таким образом, что если смех вообще открывает конфликт иллюзии и реальности, то ум переносит от первого ко второму. Но при этом смех - это разоблачение, которое не простирается на смеющегося: для последнего открывается истинное лицо окружающих. (Здесь уместно вспомнить определение смеха Т. Гоббсом как «чувства превосходства»). Когда же разоблачение касается жизни самого героя - ему не до смеха. Так, уже упомянутая нами история тетушки Софии (разоблачение того, что героиня «хотела схоронить») сопровождается хохотом Лизы. Но то же самое, примеренное Софией к себе, вызывает огорчение: «Вот так же обо мне потом заговорят!» Причем нечто похожее с Софией и происходит. Шутовство Максима Петровича, который был «высочайшею пожалован улыбкой» $(2,2)$, на первый взгляд, противоречит тому, что осмеиваемый оказывается в ситуации разоблачения горестной истины. Однако здесь необходимо учесть то, что это не разоблачение, а, наоборот, сознательное самооблачение. Шутовская (дурацкая) маска поэтому связана не с горем, а с благополучием («пожалован»).

Большая часть образов смеха связана с Чацким. Он и сам смеется, и становится предметом насмешек. Но здесь важно отметить следующую закономерность. В начале пьесы (еще до своего появления) Чацкий отрекомендован как насмешник («чувствителен, и весел, и остер»; «пересмеять умеет всех»; «верно счастлив там, где люди посмешнее» $(1,5))$. В расспросах героя о Москве $(1,7)$ доминирует именно насмешливый тон. Но затем все меняется. Постепенное прояснение горестной истины собственного положения сопровождается обращением смеха на самого насмешника. Распускание Софией слуха о сумасшествии Чацкого является именно мстительной шуткой:

А, Чацкий! Любите вы всех в шуты рядить, Угодно ль на себе примерить? $(3,14)$ 
В конце третьего действия Чацкий рассказывает о своей встрече с «французиком из Бордо», которая заканчивается смехом:

Вообразите, тут у всех

На мой же счет поднялся смех... $(3,22)$

Рассказываемое событие совпадает с тем, что происходит в момент рассказывания:

Я, рассердясь и жизнь кляня,
Готовил им ответ громовый;
Но все оставили меня... $(3,22)$

В конце монолог прерывается: герой обнаруживает, что его опять все оставили.

Причем последнее слово прерванного монолога - «глядь...». Это символический жест обнаружения горестной правды проклинаемой жизни, насмехающейся над героем.

Сделанные наблюдения обнаруживают закономерность сближения понятий «ум» и «горе» в названии. Но при этом их смысл оказывается сложным и не столько «прикрепленным» к фигуре Чацкого, сколько открывающимся в художественной логике, которая объединяет всех персонажей и все ситуации пьесы Грибоедова.

\section{Литература}

Грибоедов А.С. Комедии. Драматические сцены. Л.: Искусство, 1987.

Тюпа В.И. Произведение и его имя // Литературный текст: проблемы и методы исследования. Вып. 6. Аспекты теоретической поэтики. М.; Тверь, 2000. 